\title{
Amelioration of influenza virus-induced reactive oxygen species formation by epigallocatechin gallate derived from green tea
}

\author{
Jia-xin LING\#, Fei WEI", Ning LI, Jin-lin LI, Liang-jun CHEN, Yuan-yuan LIU, Fan LUO, Hai-rong XIONG, Wei HOU, \\ Zhan-qiu YANG* \\ State Key Laboratory of Virology/Institute of Medical Virology/Research Center of Food and Drug Evaluation/State Laboratory of \\ Antiviral and Tumor of Traditional Chinese Medicine, School of Medicine, Wuhan University, Wuhan 430071, China
}

Aim: To study whether epigallocatechin gallate (EGCG), a green tea-derived polyphenol, exerted anti-influenza A virus activity in vitro and in vivo.

Methods: Madin-Darby canine kidney (MDCK) cells were tested. The antiviral activity of EGCG in the cells was determined using hemagglutination assay and qPCR. Time of addition assay was performed to determine the kinetics of inhibition of influenza A by EGCG. The level of reactive oxygen species (ROS) were determined with confocal microscopy and flow cytometry. BALB/c mice were treated with EGCG $\left(10,20\right.$ or $\left.40 \mathrm{mg} \cdot \mathrm{kg}^{-1} \cdot \mathrm{d}^{-1}, \mathrm{po}\right)$ for $5 \mathrm{~d}$. On the 3rd d of the treatment, the mice were infected with influenza A virus. Histopathological changes, lung index and virus titers in the lungs were determined.

Results: Treatment of influenza A-infected MDCK cells with EGCG (1.25-100 nmol/L) inhibited influenza A replication in a concentration-dependent manner (the $\mathrm{ED}_{50}$ value was $\left.8.71 \pm 1.11 \mathrm{nmol} / \mathrm{L}\right)$. Treatment with $\mathrm{EGCG}(20 \mathrm{nmol} / \mathrm{L})$ significantly suppressed the increased ROS level in MDCK cells following influenza A infection. In BALB/c mice infected with influenza virus, oral administration of EGCG (40 $\mathrm{mg}^{\mathrm{kg}} \mathrm{k}^{-1} \cdot \mathrm{d}^{-1}$ ) dramatically improved the survival rate, decreased the mean virus yields and mitigated viral pneumonia in the lungs, which was equivalent to oral administration of oseltamivir (40 $\mathrm{mg} \cdot \mathrm{kg}^{-1} \cdot \mathrm{d}^{-1}$ ), a positive control drug.

Conclusion: The results provide a molecular basis for development of EGCG as a novel and safe chemopreventive agent for influenza A infection.

Keywords: influenza A virus; epigallocatechin gallate (EGCG); oseltamivir; antiviral agent; ROS

Acta Pharmacologica Sinica (2012) 33: 1533-1541; doi: 10.1038/aps.2012.80; published online 3 Sep 2012

\section{Introduction}

Influenza A virus (FluA) causes seasonal flu epidemics in most regions of the world. The virus leads to substantial mortality and economic losses worldwide, with 200000 annual hospitalizations in the $\mathrm{US}^{[1,2]}$ and 500000 additional deaths globally per year; the number of deaths reaches millions in some pandemic years $^{[3]}$. The FluA is an enveloped, negative-strand RNA virus with an eight-segmented genome. The genome allows viral evasion of prophylactic strategies through mutation or reassortment and subsequent antigenic variation ${ }^{[4]}$. Significant changes occur in the virus over time and sometimes lead to the occurrence of lethal strains. Vaccines have been extensively used as the primary prophylactic agents in the prevention and

\footnotetext{
\# These authors contributed equally to this paper.

* To whom correspondence should be addressed.

E-mail zqyang@whu.edu.cn

Received 2012-04-02 Accepted 2012-05-22
}

treatment of influenza infection worldwide. In most people, vaccines afford protection only against strains of influenza that are genetically similar to those in the vaccine ${ }^{[5]}$. Thus, vaccines must be updated regularly to incorporate the most recent or seasonal antigenic strains ${ }^{[6]}$. In addition to vaccination, other strategies involve the use of antiviral compounds in the treatment of influenza infection. Neuraminidase inhibitors (NAIs), such as oseltamivir (Tamiflu) and zanamivir (Relenza) are two FDA-approved drugs for the treatment of type A and type B influenza infections ${ }^{[7]}$. However, oseltamivir-resistant mutant (H1N1) viruses were detected and found to be quickly transmitted in several countries during the 2007 and 2008 influenza seasons, which has brought attention to the unpredictable consequences of mutational resistance to anti-viral compounds in the prevention and control of flu pandemics ${ }^{[8-11]}$.

Compounds derived from herbal medicine have been broadly used as anti-influenza agents worldwide. As the most abundant catechin, making up more than half of green 
tea polyphenols, epigallocatechin gallate (EGCG) accounts for the majority of the potential health benefits brought about by green tea consumption. Extensive laboratory and communitybased epidemiological studies have described a wide range of actions of EGCG, including antioxidant, antiallergic, antibacterial, antitumor and antiviral activities ${ }^{[12]}$. However, the mechanisms of action of EGCG against FluA, such as whether EGCG acts directly on molecular components of the virus or upon cellular events necessary for the viral life cycle, remain incompletely defined.

Oxidative stress in the form of excessive production of reactive oxygen species (ROS) has been implicated in the pathogenesis of both acute and chronic inflammatory diseases, including viral infection. Evidence regarding ROS-mediated pathogenesis during viral replication has led to increased interest in the role of oxidative stress in neuroAIDS, chronic hepatitis $\mathrm{C}$ virus (HCV)-induced hepatocellular carcinoma, respiratory syncytial virus infection, and coxsackievirus B3 (CVB3)-mediated myocarditis, as well as influenza A virusinduced lung inflammation ${ }^{[13-15]}$. Therefore, compounds that modulate ROS and free radical formation might successfully diminish inflammation and hence viral pathogenesis.

In the present study, we systematically investigated the antiinfluenza A activity of EGCG in vitro and in a mouse model of influenza infection. We demonstrated that EGCG inhibits influenza A replication in a concentration- and time-dependent manner. We further determined that the observed antiinfluenza activity of EGCG might correlate with its antioxidant properties. Moreover, oral administration of EGCG to mice significantly mitigated influenza A-induced viral pneumonia and reduced viral titers in the lungs. These findings may pave the way for the use of EGCG as a therapeutically effective antiviral that combats influenza A virus infection.

\section{Materials and methods}

\section{Cells, chemicals and virus stocks}

Madin-Darby canine kidney (MDCK) cells were propagated in Dulbecco's modified Eagle's medium (DMEM) supplemented with $10 \%$ fetal calf serum (Gibco), penicillin (100 IU/mL), streptomycin $(100 \mu \mathrm{g} / \mathrm{mL})$ and $0.1 \% \mathrm{~L}$-glutamine. EGCG was purchased from Sigma-Aldrich (St Louis, MO, USA) and was $>98.0 \%$ pure. The compound was initially dissolved in $0.05 \%$ dimethyl sulfoxide (DMSO) and stored at $4{ }^{\circ} \mathrm{C}$ until use. DMSO at $0.05 \%$ was used as a negative control. Oseltamivir capsules were purchased from Roche and used as a positive control for in vivo experiments. Influenza A virus (A/ Yamagata/120/86 [H1N1]) was kindly provided by Prof Shiro SHIGETA from the Department of Microbiology, Fukushima Medical University, School of Medicine (Japan). The virus was propagated in the allantoic cavity of 10-d-old embryonic chicken eggs three times, with a hemagglutination titer above $1: 320$, as tested by hemagglutination of guinea pig red blood cells, and then stored at $-80^{\circ} \mathrm{C}$.

\section{Assessment of cytotoxicity}

MDCK cell viability in the presence of various concentrations of EGCG was evaluated using the MTT assay as described previously ${ }^{[16]}$. Briefly, cells were treated with doses of EGCG ranging from $1.25-100 \mathrm{nmol} / \mathrm{L}$ for $30 \mathrm{~h}$, and cytotoxicity was quantitated in a conventional microplate reader at $490 \mathrm{~nm}$ according to the manufacturer's protocol. The toxic dose for $50 \%$ cell death $\left(\mathrm{TD}_{50}\right)$ of EGCG was calculated.

\section{Virus growth inhibition assay}

Measurement of virus growth inhibition was performed to determine the cytoprotective effect of EGCG, as described elsewhere $^{[17]}$. Cell culture plates with 96-wells were used, and monolayers of one-day-old MDCK cells were infected with 100 median tissue culture infective dose $\left(\mathrm{TCID}_{50}\right)$ of influenza A virus. After $2 \mathrm{~h}$ of adsorption at $4^{\circ} \mathrm{C}$, the cells were overlaid with $0.2 \mathrm{~mL}$ of serum-free DMEM containing EGCG at various concentrations (two-fold dilutions starting from $20 \mathrm{nmol} / \mathrm{L}$ ) and returned to $37^{\circ} \mathrm{C}$. Every $28 \mathrm{~h}$ after infection, the antiviral activity was measured with the MTT assay by evaluation of the therapeutic index [TI=toxic dose for $50 \%$ cell death $\left(\mathrm{TD}_{50}\right)$ / effective dose for $50 \%$ reduction on viral replication $\left.\left(\mathrm{ED}_{50}\right)\right]^{[16]}$.

\section{Time of addition assay}

Time of addition assay was performed according to the method described previously ${ }^{[18]}$. Briefly, MDCK cell monolayers in 24-well plates were infected with 100 TCID $_{50}$ of FluA at $4{ }^{\circ} \mathrm{C}$ for $2 \mathrm{~h}$ to allow viral adsorption. Unbound virus was removed from the monolayers with three washes of PBS. The cells were overlaid with fresh medium for further incubation. Twenty micromolar EGCG was added to the infected cells immediately or at $2,4,6,8,10,14,18,22$, and 26 h postinfection. Culture supernatants were collected to determine the virus yields by hemagglutination. The infected cells were harvested for quantification of vRNA by qPCR.

\section{Quantification of viral RNA by real-time quantitative PCR (qPCR)} Total intracellular RNA was isolated with TRIzol reagent (Invitrogen) from 24-well plates. Quantification of influenza A viral RNA within virus-infected and EGCG-treated cells was performed by qPCR as described by Chidlow et al ${ }^{[19]}$. Primers were specific for $\mathrm{M}$ segments of FluA. Canine and mouse glyceraldehyde-3-phosphate dehydrogenase (GAPDH) were used as reference genes in vitro and in vivo, respectively. The primer sequences were as follows: influenza A M forward 5'-ACCCAGAAGACTGTGGATGG-3', reverse 5' ACACATTGGGGGTAGGAACA-3'; canine GAPDH forward 5'-GGTGGTCCTCTGACTTCAACA-3' , reverse 5'-GTTGCTGTAGCCAAATTCGTTGT-3'; mouse GAPDH forward 5' AGGGCATTTTGGACAAATCGTCTA-3', and reverse 5' -GACCAATCCTGTCACCTCTGAC-3'. qPCRs were performed in triplicate for each sample, and the fluorescence emission of each cycle was monitored and analyzed using Bio-Rad CFX manager software.

\section{Hemagglutination assay}

All supernatants from the virus growth inhibition assay were collected and used for titration of infectious virus by hemag- 
glutination of guinea pig red blood cells. Briefly, supernatants were serially diluted 10-fold and incubated with an equal volume of $1 \%$ guinea pig red blood cell suspension. After incubation, viral titers were calculated as previously described ${ }^{[17]}$.

\section{Reactive oxygen species (ROS) detection}

Following infection with FluA, MDCK cells were either left untreated or treated with $20 \mathrm{nmol} / \mathrm{L}$ EGCG over a period of $28 \mathrm{~h}$. ROS generated in MDCK cells were measured by using an intracellular ROS indicator, 2', $7^{\prime}$-dichlorofluorescindiacetate (H2DCF-DA, Sigma-Aldrich, St Louis, MO, USA), according to the manufacturer's protocols. Detection of $2^{\prime}, 7^{\prime}$-dichlorofluorescein (DCF) was carried out by flow cytometry on an EPICS ALTRA II (Beckman).

MDCK cells were cultured on a glass-bottom culture dish (MatTek, USA). To visualize ROS formation, we microscopically examined DCF fluorescence. Mitochondria were livestained with $100 \mathrm{nmol} / \mathrm{L}$ Mitotracker Red CMXRos (Invitrogen). The cells were then washed with PBS twice and fixed in a $4 \%$ paraformaldehyde (PFA) solution for $20 \mathrm{~min}$ before examination under a confocal microscope (Leica TCS SP5).

\section{Animals and viral titration}

Specific pathogen-free BALB/c mice aged between 4 and 6 weeks were purchased from Animal Research Center of Wuhan University (Certificate No SCXK 2008-0004, Wuhan, China). The welfare of all animals used in the experiments was in compliance with the relevant guidelines and internationally accepted principles of the Institutional Animal Care and Use Committee (Wuhan, China). Mice were anesthetized intraperitoneally by ketamine $(100 \mathrm{mg} / \mathrm{kg})$ and inoculated intranasally with $50 \mu \mathrm{L}$ serial ten-fold dilutions $\left(1: 1\right.$ to $\left.1: 10^{-4}\right)$ of the FluA (FM1 strain). The median lethal dose $\left(\mathrm{LD}_{50}\right)$ of virus was determined based on the mortality rate of animals according to the Reed-Muench method ${ }^{[20]}$.

\section{Influenza virus infections and EGCG treatment in mice}

The mice were randomly divided into 6 groups: mice treated with EGCG at doses of 40,20 , and $10 \mathrm{mg} \cdot \mathrm{kg}^{-1} \cdot \mathrm{d}^{-1}$ were designated as high, middle and low-dose groups, respectively; the positive controls received $40 \mathrm{mg} \cdot \mathrm{kg}^{-1} \cdot \mathrm{d}^{-1}$ oseltamivir; the virus controls and the normal controls without viral infection received no treatment. BALB/c mice were infected intranasally with $25 \mu \mathrm{L}$ viral suspension per nostril containing $10 \mathrm{LD}_{50}$ of influenza A (FM1 strain). The treatment of EGCG was begun $2 \mathrm{~d}$ before virus inoculation. After $2 \mathrm{~h}$, EGCG at designated concentrations was orally administered to each group for 5 consecutive days. Individual mouse weights were recorded for $15 \mathrm{~d}$, and surviving mice were sacrificed by exsanguination at the end of the experiment. The lungs were harvested, weighed and used to determine the viral titers. The lung index was calculated as the ratio of mean lung weight to mean body weight.

\section{Histopathology}

The right lung lobes were removed from the thorax and fixed in $10 \%$ buffered formaldehyde. After embedding in low-melting-point paraffin wax, 3-4 $\mathrm{mm}$ sections were cut and stained with hematoxylin and eosin (H\&E) to assess general histopathology as described elsewhere.

\section{Statistical analysis}

Each set of experiments was repeated at least three times with consistent results. The data were analyzed with the SPSS 17.0 software package (SPSS Inc, Chicago, IL, USA). The results were presented as the mean \pm standard deviation (SD) and examined by the two-sample test or one-way analysis of variance. Student's $t$ test for paired samples was used to determine significance. $P$ values $<0.05$ were considered significant.

\section{Results}

Dose-dependent effects of EGCG on viral titer and replication in vitro

To evaluate the antiviral effect of EGCG on FluA, we tested its ability to inhibit the production of infectious progeny virus in MDCK cells. The chemical structure and cytotoxicity of EGCG is shown in Figure 1A. Following EGCG treatment with the $\mathrm{TD}_{50}$ of approximately $81.18 \pm 9.90 \mathrm{nmol} / \mathrm{L}$, the influenza A-induced cytopathic effect (CPE), normally apparent at 20-26 h post-infection, was dramatically delayed compared to virus-only controls. Treatment with $20 \mathrm{nmol} / \mathrm{L}$ and $10 \mathrm{nmol} / \mathrm{L}$ EGCG induced dramatic decreases in infectious virions as assayed by hemagglutination, without any visible changes in cell morphology or cell density, and in the absence of CPE (Figure 1B, 1C). In addition, qPCR analysis showed a dose-dependent decrease in viral RNA level in EGCG-treated groups from 20 to $1.25 \mathrm{nmol} / \mathrm{L}\left(\mathrm{R}^{2}=0.9500, P<0.0001\right)$ (Figure 1D). The effective dose for $50 \%$ reduction of viral replication $\left(\mathrm{ED}_{50}\right)$ by EGCG was $8.71 \pm 1.11 \mathrm{nmol} / \mathrm{L}$. The in vitro value of the therapeutic index $\left(\mathrm{TI}=\mathrm{TD}_{50} / \mathrm{ED}_{50}\right)$ of EGCG was 9.32 .

\section{Kinetics of inhibition of influenza A by EGCG in vitro}

As described above, EGCG treatment caused a dose-dependent reduction of both viral RNA levels and infectious progeny in the supernatant. To determine whether inhibition of influenza A replication and production of infectious progeny by EGCG was time-dependent, the compound was added immediately after virus inoculation or at the indicated time. The growth of FluA on MDCK cells was measured over time by hemagglutination and qPCR. The influenza A virus replicated efficiently in cultured MDCK cells, and virus levels peaked at 28-30 h post-infection (Figure 2A). MDCK cells were inoculated with $100 \mathrm{TCID}_{50}$ FluA and treated with $20 \mathrm{nmol} / \mathrm{L}$ EGCG immediately or 2, 4, 6, 8, 10, 14, 18, 22, and $26 \mathrm{~h}$ post-infection at $37^{\circ} \mathrm{C}$. The production of viral RNA was analyzed by qPCR, and infectious particles in the supernatant were quantitated by hemagglutination at $28 \mathrm{~h}$ post-infection. We found that EGCG significantly inhibited influenza A replication when added 0-4 h after virus inoculation (Figure 2B, 2C). Maximum inhibition, corresponding to an approximately 130-fold decrease in hemagglutination titers, was observed when EGCG was added immediately after virus inoculation 
A<smiles>O=C(OC1Cc2c(O)cc(O)cc2OC1c1cc(O)c(O)c(O)c1)c1cc(O)c(O)c(O)c1</smiles>
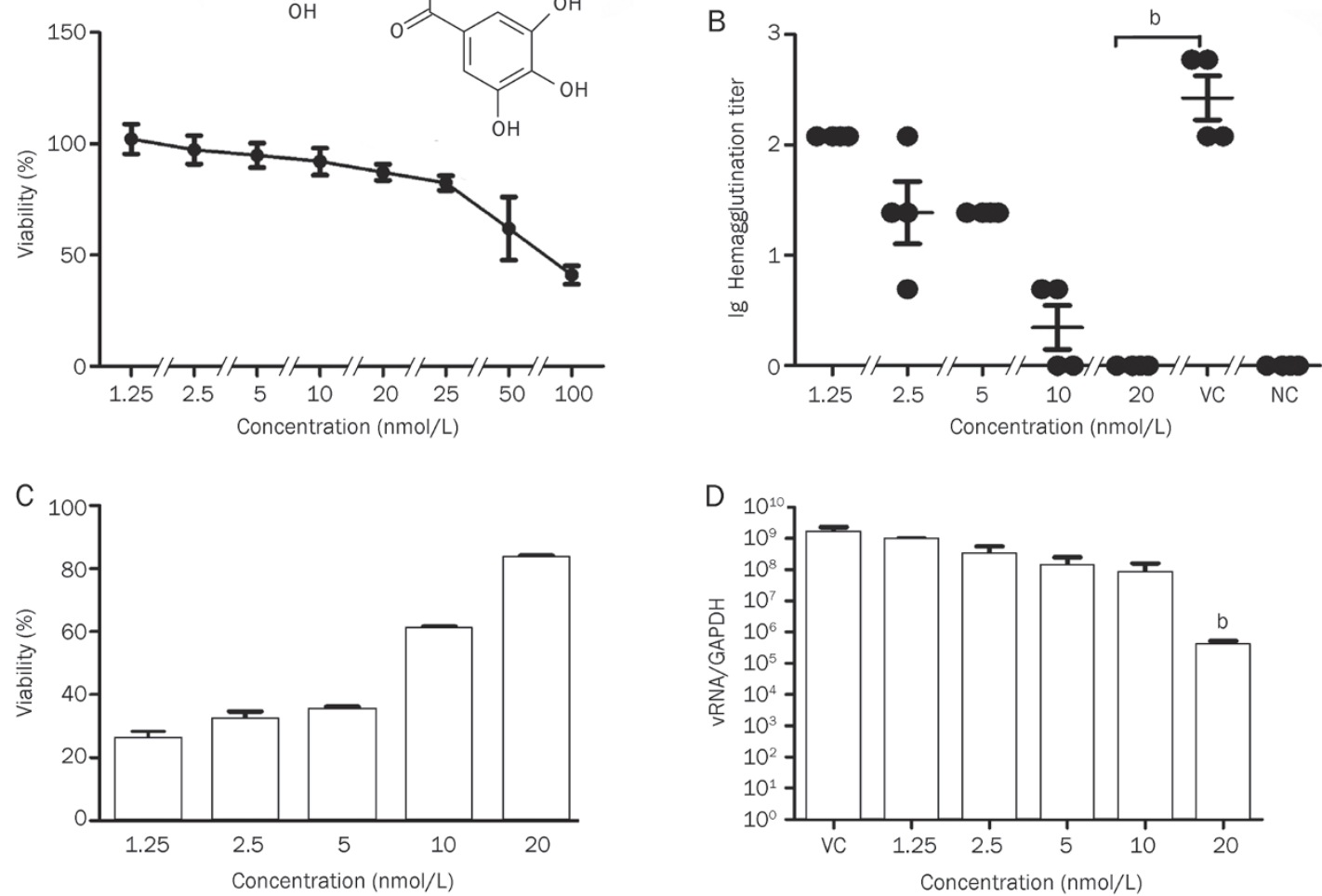

Figure 1. EGCG suppresses influenza A replication and cellular toxicity. (A) Cellular toxicity of EGCG. MTT assay was performed to determined cellular toxicity of EGCG on MDCK cells. (B) Dose-response curves showing the yield of infectious virus in the supernatants following EGCG treatment. Hemagglutination titers were determined as described in Material and methods. (C) Anti-influenza A effect of EGCG. Cell viability of influenza-infected, EGCG-treated cells was determined. Each data point represents the mean \pm standard deviation (SD) from three independent experiments. (D) Doseresponse curves showing influenza vRNAs following EGCG treatment. After inoculation with $100 \mathrm{TCID}_{50}$ influenza A virus, MDCK cells were either left untreated (control) or treated with EGCG at several concentrations over a period of $28 \mathrm{~h}$. Cell lysates were measured for vRNAs level. ${ }^{\mathrm{b}} \mathrm{P}<0.05$ as determined by the treatment vs viral control (VC).

when the cells were placed at $37^{\circ} \mathrm{C}$. However, pre-treatment of MDCK cells with EGCG for $2 \mathrm{~h}$ had no direct effect on the reduction of influenza A replication (data not shown). Notably, inhibition of influenza A by EGCG was significant when added at 2, 4, and $6 \mathrm{~h}$ post-infection, with reductions in infectious virus of 100-, 57-, and 45-fold, respectively (Figure 2B). The decrease of viral RNAs in the cell lysates and reduction of infectious virus in the supernatants show similar temporal patterns. These results demonstrate that the main effect of EGCG may occur at an early stage in the virus replication cycle, after virus adsorption to the host cell.

\section{Effects of EGCG treatment on virus-induced changes in redox} potential in vitro

Elevated mitochondrial superoxide and ROS production were previously observed in both human airways and MDCK cells following influenza infection. To assess the relationship between antioxidant properties of EGCG and its antiviral activity, intracellular ROS levels were quantitated in H2DCFDA-loaded, influenza-infected MDCK cells in the presence or absence of $20 \mathrm{nmol} / \mathrm{L}$ EGCG. An increased accumulation of intracellular ROS level in cells infected with FluA was observed, which is consistent with previous studies ${ }^{[21]}$. ROS production appeared to be mitochondrial in origin, and 20 nmol/L EGCG treatment could efficiently quench virusinduced ROS generation (Figure 3A). Flow cytometry and confocal microscopy showed a substantial $54 \%$ decrease in the density of DCF fluorescence in the influenza A-infected, EGCG-treated cells (Figure 3B, 3C). Similar ROS reduction occurred in mock-infected MDCK cells following EGCG treatment (mean fluorescence intensity (MFI) decreased from 71.43 to $19.81 \%$ ) (Figure 3C). These results collectively suggest that EGCG, which is a potent ROS scavenger, may slowly reduce ROS levels in MDCK cells, which could in turn diminish effi- 
A

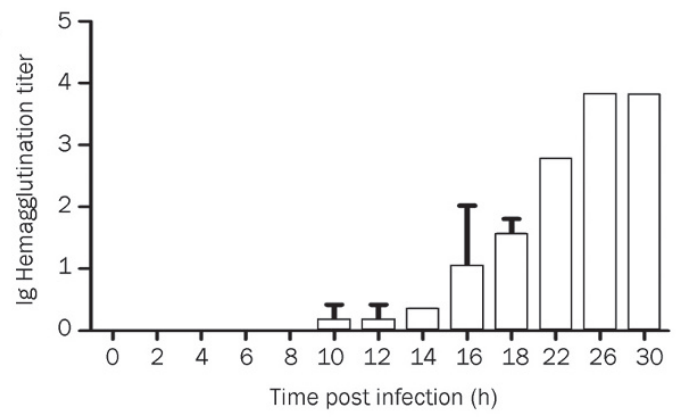

B

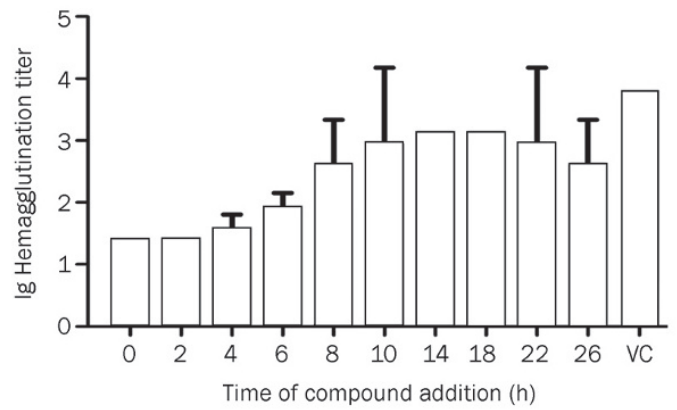

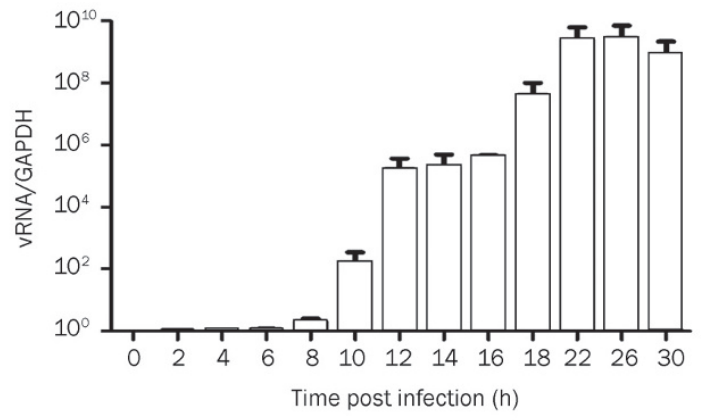

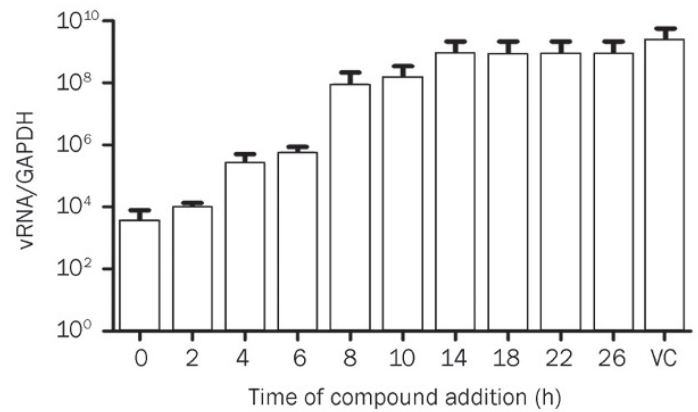

C
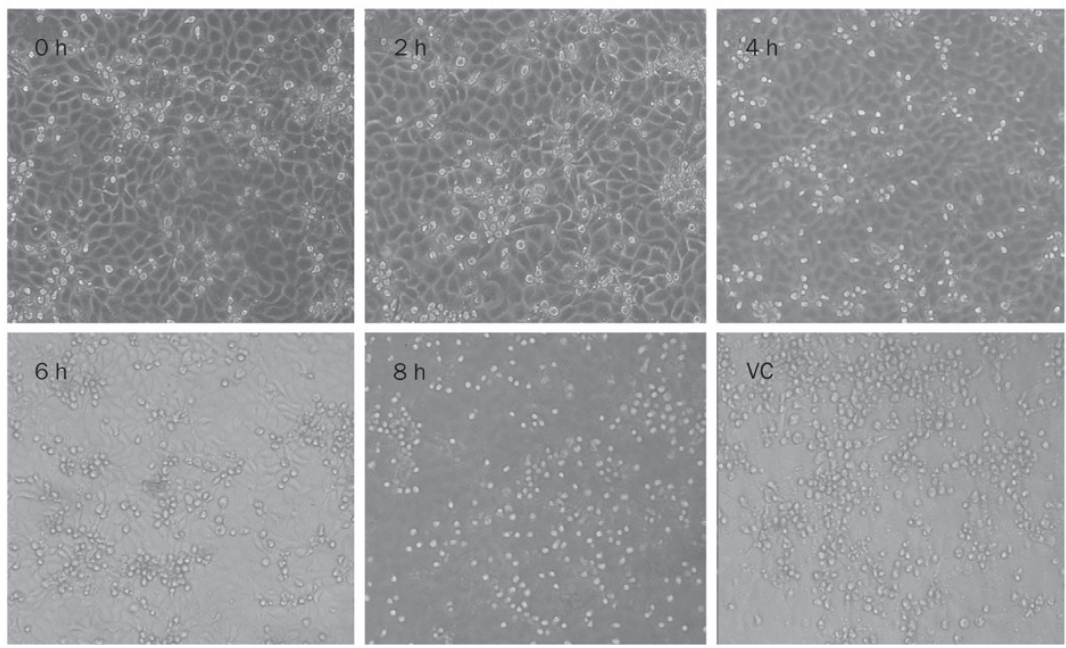

Figure 2. EGCG inhibits influenza A infection at the initial stage of viral replication. (A) Single kinetic growth curves of influenza A virus on MDCK cells. MDCK cells were infected with $100 \mathrm{TCID}_{50}$ influenza A virus for $2 \mathrm{~h}$ at $4^{\circ} \mathrm{C}$. After removing unbound virus, cells were replaced with serum-free medium. Supernatants and cell lysates were collected at the indicated times (at 0, 2, 4, 6, 8, 10, 12, 14, 16, 18, 20, 22, 24, 26, and 30 h post-adsorption). Viral RNAs were extracted and quantified by qPCR. Supernatants were used to determine virus titers by hemaglutination assay. (B) Time-of-addition assay. After $2 \mathrm{~h}$ at $4^{\circ} \mathrm{C}$ to allow virus binding but not virus entry, the infected cells were treated with $20 \mathrm{nmol} / \mathrm{L} \mathrm{EGCG}$ at the indicated times (immediately or at 2,4 , $6,8,10,14,18,22$, and $26 \mathrm{~h}$ post-adsorption) until supernatants and cell lysates were collected at $28 \mathrm{~h}$ post-infection. Total viral RNAs were extracted from cell lysates, reverse transcribed and assayed by qPCR as described in Materials and methods. Supernatants were used for hemagglutination assay. Data are presented as mean $\pm S D$ of results from three independent experiments. (C) Cytoprotection effect of EGCG by time-of-addition assay. Light microscopy images were captured at an original magnification of $\times 200$. VC indicates viral controls.

cient viral production.

\section{Oral administration of EGCG ameliorates the clinical signs of} influenza infection in a murine model

After death rates were evaluated for $14 \mathrm{~d}$ post-infection, $\mathrm{LD}_{50}$ was determined to be $10^{2.33}$ by the Reed-Muench method. Mice infected intranasally with the $\mathrm{LD}_{50}$ of FluA were treated with different concentrations of EGCG: high dose $40 \mathrm{mg} \cdot \mathrm{kg}^{-1} \cdot \mathrm{d}^{-1}$; middle dose $20 \mathrm{mg} \cdot \mathrm{kg}^{-1} \cdot \mathrm{d}^{-1}$; low dose $10 \mathrm{mg} \cdot \mathrm{kg}^{-1} \cdot \mathrm{d}^{-1}$. Clinical signs of murine influenza-induced pneumonia, which were initially observed at $\mathrm{d} 3$ post-inoculation, were sluggishness, ruffled fur, and anorexia as well as the tendency to huddle. 

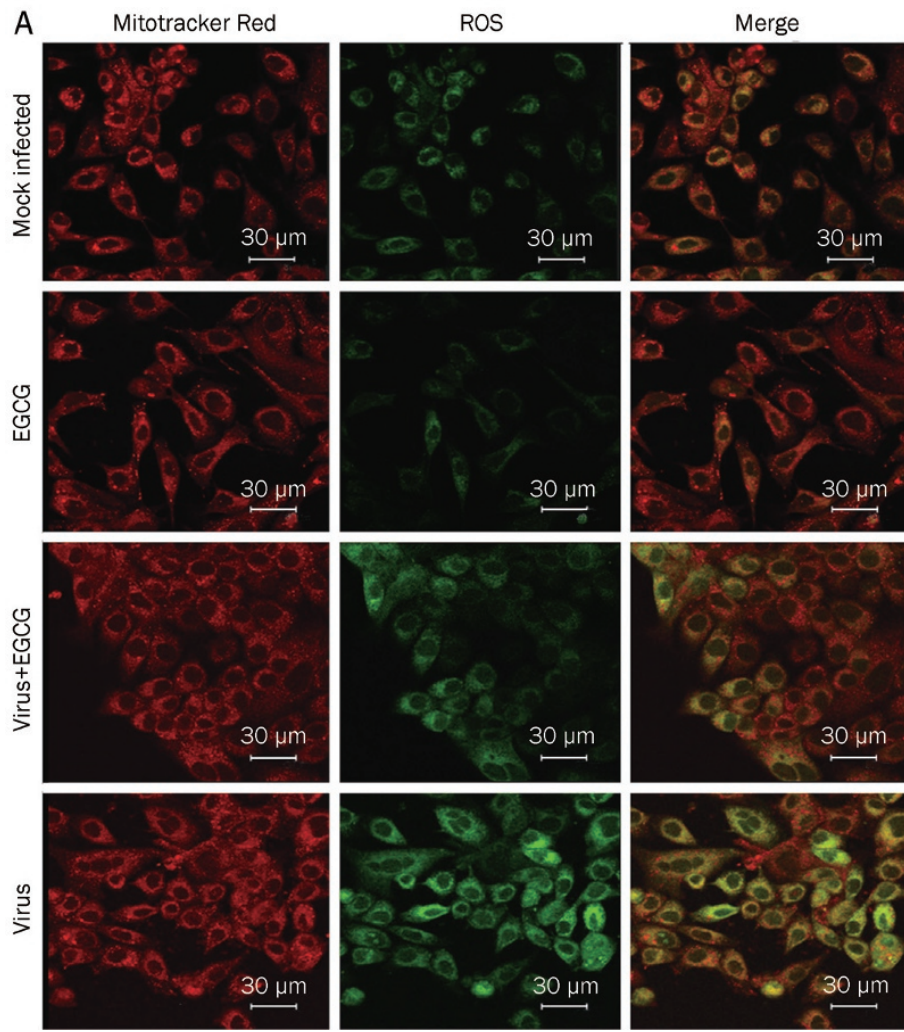
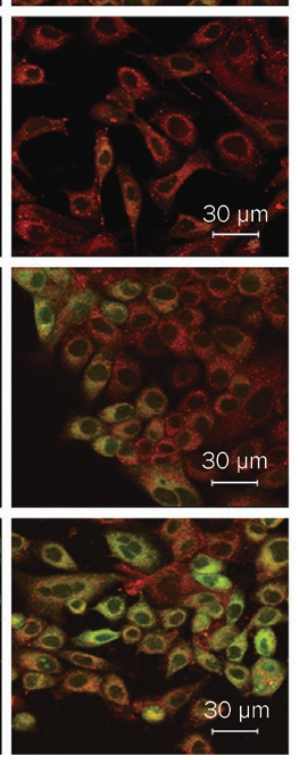

B
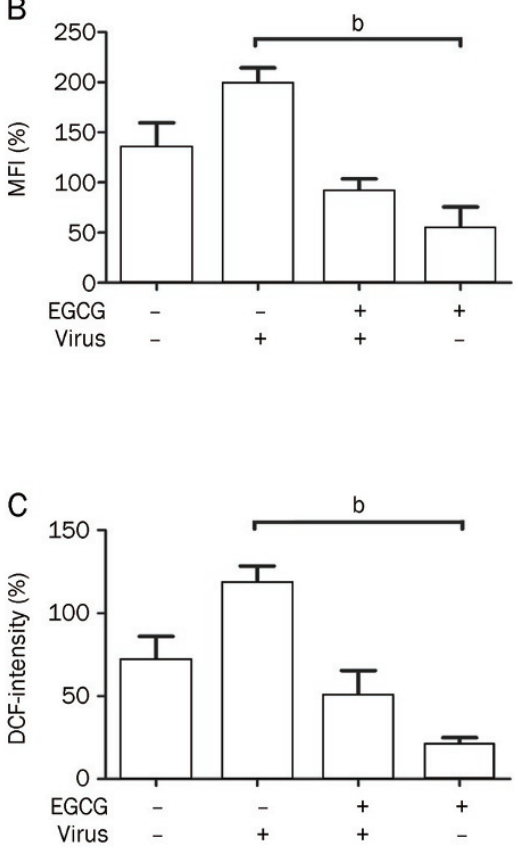

Figure 3. Analysis of reactive oxygen species (ROS) production in EGCG treated MDCK cells. (A) EGCG treatment ameliorates ROS overproduction in influenza infected cells. MDCK cells were double stained with Mitotracker Red CMXRos and dichlorofluorescein (H2DCF-DA) and microscopically visualized under confocal microscope (Scale bar, $30 \mu \mathrm{m}$ ). (B) MDCK cells were uninfected or infected with 100 TCID $_{50}$ influenza $A$ virus and untreated or treated with $20 \mathrm{nmol} / \mathrm{L}$ EGCG. Mean fluorescence intensity (MFI \%) of each group was determined. The results are presented as the mean \pm SD of three experiments. (C) Flow cytometry analysis of ROS levels. Cells were washed with serum-free DMEM and incubated in serum-free medium containing 10 $\mu \mathrm{mol} / \mathrm{L} \mathrm{H} 2 \mathrm{DCF}-\mathrm{DA}$ for $30 \mathrm{~min}$ at $37^{\circ} \mathrm{C}$. DCF-intensity was determined by flow cytometry. Each bar represents the mean \pm SD of the three independent experiments. ${ }^{\mathrm{b}} \mathrm{P}<0.05$ as determined by the treatment $v s$ viral control.

These signs were especially evident in untreated control mice. By d 10 following influenza infection, all untreated mice succumbed to illness with dramatic losses of body weight and decreased vitality. In contrast, significant numbers of mice survived in groups treated with the high and middle doses of EGCG, with only $33.3 \%$ and $50 \%$ of mice, respectively, succumbing to infection. The antiviral effect of the high dose EGCG was equivalent to $40 \mathrm{mg} \cdot \mathrm{kg}^{-1} \cdot \mathrm{d}^{-1}$ Oseltamivir administration (Table 1). Except in the case of the low-dose treatment

Table 1. Oral administration of EGCG alleviates influenza-induced lethality in BALB/c mice.

\begin{tabular}{lccccc}
\hline Group & $\begin{array}{c}\text { Dose } \\
\left(\mathrm{mg}^{\mathrm{kg}} \mathbf{k}^{-1} \cdot \mathrm{d}^{-1}\right)\end{array}$ & $\begin{array}{c}\text { No of } \\
\text { mice }\end{array}$ & $\begin{array}{c}\text { No of } \\
\text { death }\end{array}$ & $\begin{array}{c}\text { Death } \\
\text { rate }(\%)\end{array}$ & $\begin{array}{c}\text { Mean days } \\
\text { death }\end{array}$ \\
\hline High & 40 & 12 & 4 & 33.3 & $12.0 \pm 2.67$ \\
Middle & 20 & 12 & 6 & 50 & $11.0 \pm 3.00$ \\
Low & 10 & 12 & 9 & 75 & $9.83 \pm 2.33$ \\
Oseltamivir capsule & 40 & 12 & 4 & 33.3 & $12.9 \pm 1.24$ \\
VC & - & 12 & 10 & 83.3 & $9.08 \pm 1.94$ \\
NC & - & 12 & 0 & 0 & - \\
\hline
\end{tabular}

of EGCG, differences between treated and untreated groups were significant (all $P<0.05)$. The lung index was used to monitor lung inflammation after viral challenge, as described in Materials and methods. The lung indexes in the high-, middle-, and low-dose groups were $0.757 \pm 0.067,0.875 \pm 0.123$, and $0.897 \pm 0.121$, respectively, while the lung index in the untreated group was $1.235 \pm 0.373$ (Figure $4 \mathrm{~A}$ ). The results clearly indicate that EGCG treatment could mitigate viral pneumonia induced by influenza infection.

\section{EGCG reduces lung viral titers in influenza-infected mice}

The differences in lung viral titers and viral M gene replication in the influenza-infected mice from different groups are shown in Figure 4. Oral administration of $40 \mathrm{mg} \cdot \mathrm{kg}^{-1} \cdot \mathrm{d}^{-1}$ and $20 \mathrm{mg} \cdot \mathrm{kg}^{-1} \cdot \mathrm{d}^{-1}$ EGCG significantly decreased viral titers in the lung by 74 -fold and 35 -fold, respectively, compared to the untreated controls $(P<0.05)$ (Figure $4 \mathrm{~B}, 4 \mathrm{C})$. The viral titer results were confirmed by real-time PCR, which showed that viral M gene RNA levels were decreased by approximately 56-fold and 41-fold in the groups treated with EGCG at 40 and $20 \mathrm{mg} \cdot \mathrm{kg}^{-1} \cdot \mathrm{d}^{-1}$, respectively, compared to the untreated controls (Figure $4 \mathrm{C}$ ). The groups treated with $40 \mathrm{mg} \cdot \mathrm{kg}^{-1} \cdot \mathrm{d}^{-1}$ and 

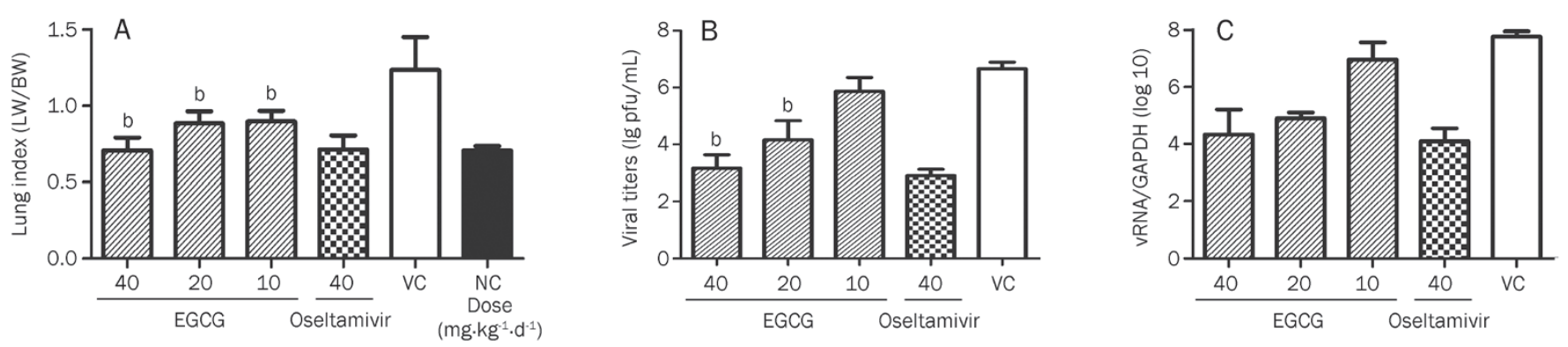

Figure 4. Mortality after influenza A infection and EGCG treatment in mice. (A) Reduction of lung index following EGCG administration in influenza A-infected mice. Mice were either treated with EGCG orally at different concentration each day or administered with $40 \mathrm{mg} \cdot \mathrm{kg}^{-1} \cdot \mathrm{d}^{-1} \mathrm{Oseltamivir}$ capsule as positive control. Lung index was expressed as the ratio of mean lung weight (LW) to mean body weight (BW), which served as an indicator for lung inflammation. Oseltamivir $40 \mathrm{mg} \cdot \mathrm{kg}^{-1} \cdot \mathrm{d}^{-1}$ was used as positive control. (B) Lung viral titers reduction following EGCG treatment. Mice were sacrificed and lungs were homogenized in ice-cold test medium. Lung virus titer was determined by plaque assay. (C) Lung viral RNAs were determined by the qPCR following the protocol described in Materials and methods. Statistical significance from viral control is determined by One-way ANOVA with Bonferroni's multiple comparison-test, ${ }^{\mathrm{b}} \mathrm{P}<0.05$.

$20 \mathrm{mg} \cdot \mathrm{kg}^{-1} \cdot \mathrm{d}^{-1}$ EGCG showed lower lung viral titers and vRNA than the EGCG group receiving only $10 \mathrm{mg} \cdot \mathrm{kg}^{-1} \cdot \mathrm{d}^{-1}(P<0.05)$.

\section{Pathological evaluation}

Microscopic evaluation demonstrated that the lungs from the uninfected groups had no changes in the pulmonary alveoli and epithelial cells. In contrast, infected lungs showed thickened alveolar walls due to the edema of alveolar epithelia, interstitial lymphocyte infiltration, and hemorrhage, indicating severe interstitial viral pneumonia. Edema of the lungs decreased significantly in the EGCG high-dose group compared to the untreated controls. The group treated with
EGCG at $20 \mathrm{mg} \cdot \mathrm{kg}^{-1} \cdot \mathrm{d}^{-1}$ had moderate lung edema and interstitial lymphocyte infiltration compared to the untreated group (Figure 5). Taken together, these data reveal that EGCG could decrease mortality and viral pneumonia following influenza A infection.

\section{Discussion}

As one of the most abundant components in green teaderived polyphenols, the biological activities of EGCG have been extensively investigated. Several studies have demonstrated the effect of EGCG on the yield of infectious FluA and determined an $\mathrm{ED}_{50}$ of $8 \mu \mathrm{mol} / \mathrm{L}$; however, the mechanism of

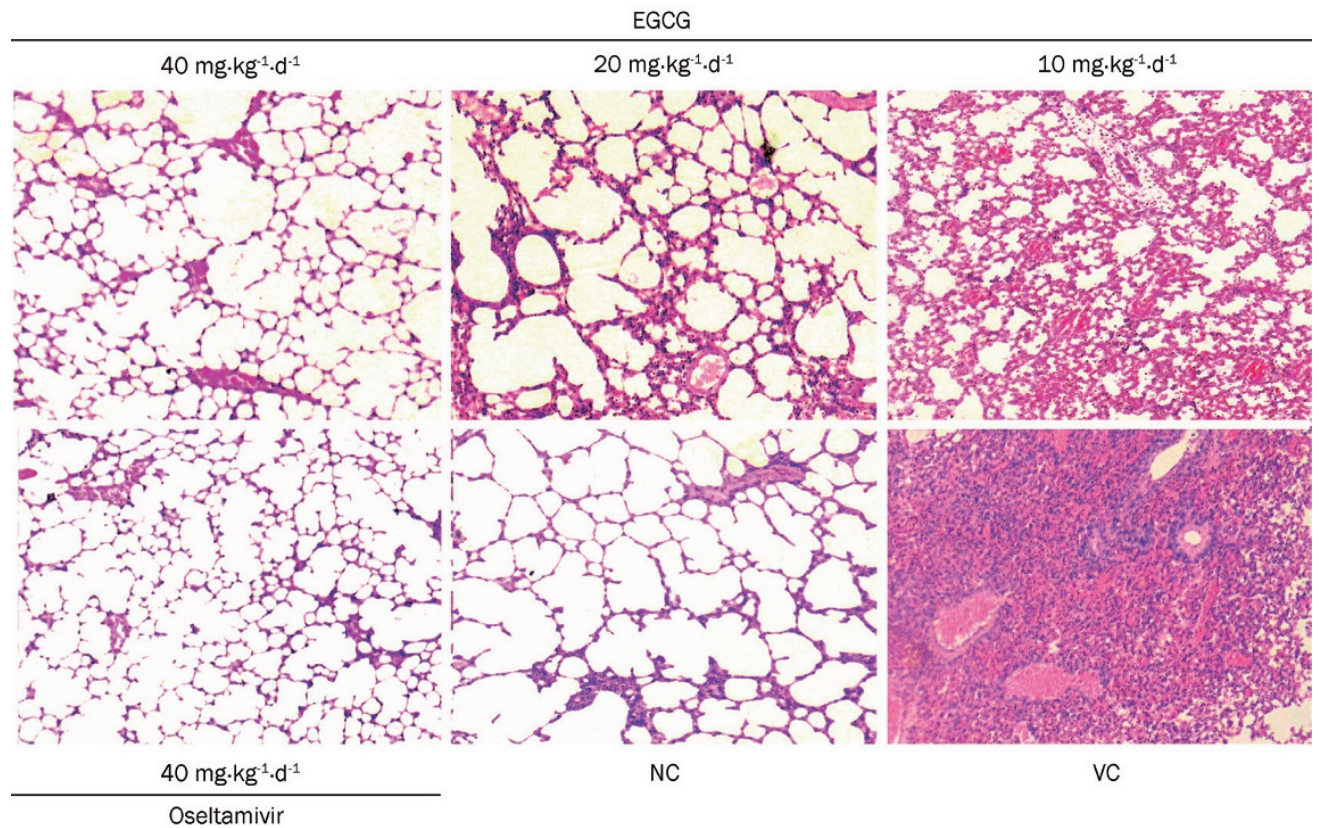

Figure 5. EGCG treatment alleviates influenza virus-induced lung lesion in mice. Photomicrographs of Hematoxylin \& Eosin-stained paraffin sections generated from infected lung treated with high dose of EGCG (40 mg. kg-1. $\left.\mathrm{d}^{-1}\right)$; middle dose $\left(20 \mathrm{mg}^{\mathrm{kg}} \mathrm{k}^{-1} \cdot \mathrm{d}^{-1}\right)$; low dose $\left(10 \mathrm{mg} \cdot \mathrm{kg}^{-1} \cdot \mathrm{d}^{-1}\right)$; Viral controls $(\mathrm{VC})$ and normal controls (NC). The EGCG treated group showed a dose-dependent reduction of influenza virus A-induced lung lesion in mice. Oseltamivir capsule $40 \mathrm{mg} \cdot \mathrm{kg}^{-1} \cdot \mathrm{d}^{-1}$ was used as positive control. 
EGCG's antiviral action needs elucidation $^{[22]}$. In the current study, a dramatic reduction in infectious progeny particles at $28 \mathrm{~h}$ post-infection, which coincided with the pattern of vRNA synthesis, was found in influenza-infected MDCK cells treated with EGCG. To gain more insight into the mechanism by which EGCG interrupts influenza virus replication, time of addition experiments were performed to determine the time point of maximum inhibition by EGCG. The maximum inhibitory effect of EGCG, which was $80 \%$ inhibition of influenza replication, was observed when EGCG was added immediately after adsorption and rapidly decreased to $29 \%$ inhibition when EGCG was added $8 \mathrm{~h}$ post-infection. No significant inhibition of infection was observed if EGCG was added $10 \mathrm{~h}$ after viral inoculation. As previously reported by $\mathrm{Kim}^{[18]}$, our data demonstrate that EGCG may interrupt the early stages of the viral replication cycle.

Elevated ROS production and oxidative stress play a pivotal role in exacerbation of various clinical conditions, such as those associated with malignant diseases, chronic inflammation, angiogenesis, and viral infection ${ }^{[14,23,24]}$. As intracellular free radicals, ROS may induce transient or permanent cellular alterations ${ }^{[25]}$. Accumulating evidence supports the association of virus-induced ROS production and increased pathogenesis following infections ${ }^{[24,26,27]} \mathrm{HCV}$ core protein could induce oxidative stress through calcium signaling pathways, which may act directly and indirectly to promote liver fibrosis and carcinogenesis ${ }^{[28]}$. Previous studies have identified several antioxidants with anti-influenza virus activity, including pyrrolidine dithiocarbamate (PDTC) and $\mathrm{N}$-acetyl-L-cysteine (NAC) ${ }^{[29]}$. In addition, compounds that act as ROS-generating agents, such as phorbol 12-myristate 13-acetate (PMA), enhance influenza proliferation in MDCK cells. As a free radical scavenger, EGCG acts as an antioxidant through alterations in ROS metabolism. Suppression of enterovirus 71 (EV71) replication by EGCG via modulation of cellular redox milieu was also reported recently ${ }^{[30]}$. Culture of influenza-infected MDCK cells in the presence of $20 \mathrm{nmol} / \mathrm{L}$ EGCG for $28 \mathrm{~h}$ post-infection resulted in a significant reduction in ROS levels compared to untreated MDCK cells. These results were corroborated by the evaluation of overproduction of ROS in MDCK cells infected with influenza virus by confocal microscopy. As has been previously suggested, ROS and/ or ERK phosphorylation are crucial for the nuclear export of influenza virus ribonucleoprotein (RNP), and diminished ROS formation can in turn inhibit influenza virus proliferation ${ }^{[29]}$.

Guided by our in vitro data, we performed a mouse study to determine the in vivo effects of EGCG on mouse-adapted FluA. EGCG administration at $40 \mathrm{mg} \cdot \mathrm{kg}^{-1} \cdot \mathrm{d}^{-1}$ significantly reduced lung vRNA levels and viral titers and resulted in better survival than the untreated mice. Quercetin and other forms of polyphenols, such as isoquercetin, have been reported to decrease free radical production during ischemic tissue damage and to reduce lung inflammation in murine pneumonia induced by influenza virus ${ }^{[24]}$. Mortality reduction in mice infected with influenza virus and treated with antioxidants has also been reported previously ${ }^{[18]}$. Our findings are in line with other studies that described suppression of viral replication and reduction of viral lung inflammation by EGCG.

In summary, we explored the possible effect of EGCG on influenza A infection to gain more insight into FluA pathogenesis and to possibly obtain new targets for antiviral therapy. The activity of EGCG is different from existing antivirals such as neuraminidase or proton pump inhibitors, suggesting that EGCG could be developed into a new class of antiviral compounds that may be effective against current drug-resistant influenza strains. Many EGCG-based commercial products have been developed for daily use against malignant or benign cancer. The excellent antiviral and anti-inflammatory activities observed in our study add further appeal to the medicinal use of EGCG or other green tea polyphenol-rich products. Green tea is one of the most widely consumed beverages across the globe. Daily consumption of green tea, alone or in combination with other antiviral therapies, is most likely beneficial for health because of its antimicrobial properties.

\section{Acknowledgements}

This work was supported by the National Mega Project on Major Drug Development (2009ZX09301-014-1), and National Natural Science Foundation of China (NSFC Project No 30873104).

\section{Author contribution}

Zhan-qiu YANG define the research theme and revised the paper; Jia-xin LING and Fei WEI designed methods and experiments, carried out the experiment, interpreted the results and wrote the paper; Ning LI, Jin-lin LI, and Liang-jun CHEN coworked on animal experiment; Yuan-yuan LIU and Fan LUO performed the pathological test, Hai-rong XIONG and Wei HOU finished part experiments in vitro.

\section{References}

1 Izurieta HS, Thompson WW, Kramarz P, Shay DK, Davis RL, DeStefano $\mathrm{F}$, et al. Influenza and the rates of hospitalization for respiratory disease among infants and young children. N Engl J Med 2000; 342: 232-9.

2 Thompson WW, Shay DK, Weintraub E, Brammer L, Bridges CB, Cox $\mathrm{NJ}$, et al. Influenza-associated hospitalizations in the United States. JAMA 2004; 292: 1333-40.

3 Fraser C, Donnelly CA, Cauchemez S, Hanage WP, Van Kerkhove MD, Hollingsworth TD, et al. Pandemic potential of a strain of influenza A (H1N1): early findings. Science 2009; 324: 1557-61.

4 Scalera NM, Mossad SB. The first pandemic of the 21st century: a review of the 2009 pandemic variant influenza A (H1N1) virus. Postgrad Med 2009; 121: 43-7.

5 Goodman AG, Heinen PP, Guerra S, Vijayan A, Sorzano CO, Gomez $\mathrm{CE}$, et al. A human multi-epitope recombinant vaccinia virus as a universal T cell vaccine candidate against influenza virus. PLoS One 2011; 6: e25938.

6 Couch RB. Prevention and treatment of influenza. N Engl J Med 2000; 343: 1778-87.

7 Moscona A. Neuraminidase inhibitors for influenza. N Engl J Med 2005; 353: 1363-73.

8 Sheu TG, Deyde VM, Okomo-Adhiambo M, Garten RJ, Xu X, Bright $\mathrm{RA}$, et al. Surveillance for neuraminidase inhibitor resistance among 
human influenza A and B viruses circulating worldwide from 2004 to 2008. Antimicrob Agents Chemother 2008; 52: 3284-92.

9 Dharan NJ, Gubareva LV, Meyer JJ, Okomo-Adhiambo M, McClinton $\mathrm{RC}$, Marshall SA, et al. Infections with oseltamivir-resistant influenza $A(H 1 N 1)$ virus in the United States. JAMA 2009; 301: 1034-41.

10 Hauge SH, Dudman S, Borgen K, Lackenby A, Hungnes O. Oseltamivirresistant influenza viruses A (H1N1), Norway, 2007-08. Emerg infect dis 2009; 15: 155-62.

11 Meijer A, Lackenby A, Hungnes O, Lina B, van-der-Werf S, Schweiger B, et al. Oseltamivir-resistant influenza virus A (H1N1), Europe, 2007-08 season. Emerg infect dis 2009; 15: 552-60.

12 Friedman M. Overview of antibacterial, antitoxin, antiviral, and antifungal activities of tea flavonoids and teas. Mol Nutr Food Res 2007; 51: 116-34.

13 Mollace V, Nottet HS, Clayette P, Turco MC, Muscoli C, Salvemini D, et al. Oxidative stress and neuroAIDS: triggers, modulators and novel antioxidants. Trends Neurosci 2001; 24: 411-6.

14 Okuda M, Li K, Beard MR, Showalter LA, Scholle F, Lemon SM, et al. Mitochondrial injury, oxidative stress, and antioxidant gene expression are induced by hepatitis $C$ virus core protein. Gastroenterology 2002; 122: 366-75.

15 Beck MA, Handy J, Levander OA. The role of oxidative stress in viral infections. Ann N Y Acad Sci 2000; 917: 906-12.

16 Shi L, Xiong H, He J, Deng H, Li Q, Zhong Q, et al. Antiviral activity of arbidol against influenza $A$ virus, respiratory syncytial virus, rhinovirus, coxsackie virus and adenovirus in vitro and in vivo. Arch Virol 2007; 152: $1447-55$.

17 Song JM, Lee KH, Seong BL. Antiviral effect of catechins in green tea on influenza virus. Antiviral Res 2005; 68: 66-74.

$18 \mathrm{Kim}$ Y, Narayanan S, Chang KO. Inhibition of influenza virus replication by plant-derived isoquercetin. Antiviral Res 2010; 88: 227-35.

19 Chidlow GR, Harnett GB, Speers DJ, Smith DW, Wang J, Yang Y. Evaluation of real-time reverse transcriptase PCR assays for detection of pandemic influenza A/H1N1 2009 virus. J Clin Microbiol 2011; 49:
3444-5.

20 Muench LJRaH. A Simple method of estimating fifty per cent edpionts. Am J Epidemiol 1938; 27: 493-97.

21 Snelgrove RJ, Edwards L, Rae AJ, Hussell T. An absence of reactive oxygen species improves the resolution of lung influenza infection. Eur J Immunol 2006; 36: 1364-73.

22 Nakayama M, Suzuki K, Toda M, Okubo S, Hara Y, Shimamura T. Inhibition of the infectivity of influenza virus by tea polyphenols. Antiviral Res 1993; 21: 289-99.

23 Jackson AC, Kammouni W, Zherebitskaya E, Fernyhough P. Role of oxidative stress in rabies virus infection of adult mouse dorsal root ganglion neurons. J Virol 2010; 84: 4697-705.

24 Vlahos R, Stambas J, Bozinovski S, Broughton BR, Drummond GR, Selemidis S. Inhibition of Nox2 oxidase activity ameliorates influenza A virus-induced lung inflammation. PLoS Pathog 2011; 7: e1001271.

25 Korenaga M, Wang T, Li Y, Showalter LA, Chan T, Sun J, et al. Hepatitis $C$ virus core protein inhibits mitochondrial electron transport and increases reactive oxygen species (ROS) production. J Biol Chem 2005; 280: 37481-8.

26 Ming-Ju H, Yih-Shou H, Tzy-Yen C, Hui-Ling C. Hepatitis C virus E2 protein induce reactive oxygen species (ROS)-related fibrogenesis in the HSC-T6 hepatic stellate cell line. J Cell Biochem 2011; 112: 233-43.

27 Baruchel S, Wainberg MA. The role of oxidative stress in disease progression in individuals infected by the human immunodeficiency virus. J Leukoc Biol 1992; 52: 111-4.

28 Tardif KD, Waris G, Siddiqui A. Hepatitis C virus, ER stress, and oxidative stress. Trends Microbiol 2005; 13: 159-63.

29 Gangehei L, Ali M, Zhang W, Chen Z, Wakame K, Haidari M. Oligonol a low molecular weight polyphenol of lychee fruit extract inhibits proliferation of influenza virus by blocking reactive oxygen species-dependent ERK phosphorylation. Phytomedicine 2010; 17: 1047-56.

30 Ho HY, Cheng ML, Weng SF, Leu YL, Chiu DT. Antiviral effect of epigallocatechin gallate on enterovirus 71. J Agric Food Chem 2009; 57 : 6140-7. 